\title{
A novel approach to the management of polyp- ectomy snare entrapment: the zip-line technique
}

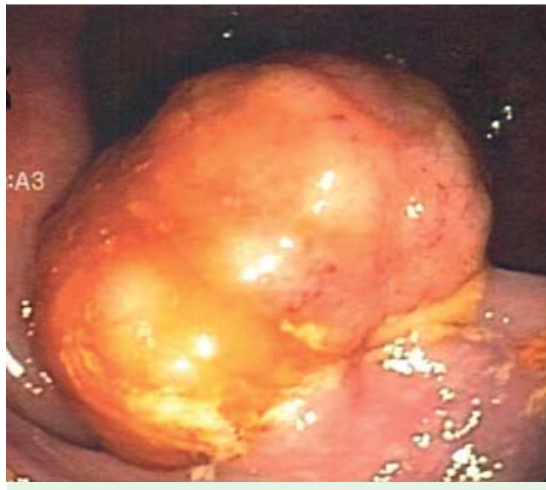

Fig. 1 Endoscopic view showing a 4-cm sessile polyp in the ascending colon.

Polypectomy-snare entrapment is a rare but serious complication of colonoscopy, frequently requiring surgical intervention. We report a case of polypectomysnare entrapment successfully treated using a novel endoscopic "zip-line" approach that, to our knowledge, has not been previously reported.

A 35-year-old woman underwent a colonoscopy in our office-endoscopy suite, during which a $4 \mathrm{~cm}$, broad-based, semipedunculated polyp was noted in the ascending colon ( $\bullet$ Fig. 1 ). After submucosal epinephrine injection into the polyp base, a $25-\mathrm{mm}$ snare was closed around the polyp and current (coagulation and then blended) was applied; however, the polyp could not be transected. The snare appeared to have become embedded in the polyp tissue and could not be opened.

The handle of the snare was now cut and, through an "exchange" technique, the colonoscope was withdrawn, leaving the wire of the entrapped snare exiting the anus. A new snare was then inserted through the colonoscope channel and the entrapped-snare wire was inserted through the open snare ( $\bullet$ Fig. 2 a), which was then partially closed and withdrawn into the colonoscope, leaving a small portion of the snare outside of the channel. The colonoscope, which at this point appeared to be "hanging" from the entrapped wire as if it were on a "zip line" ( Fig. 2b), was reinserted and easily passed to the level of the polyp ( $\bullet$ Fig. 3 a).

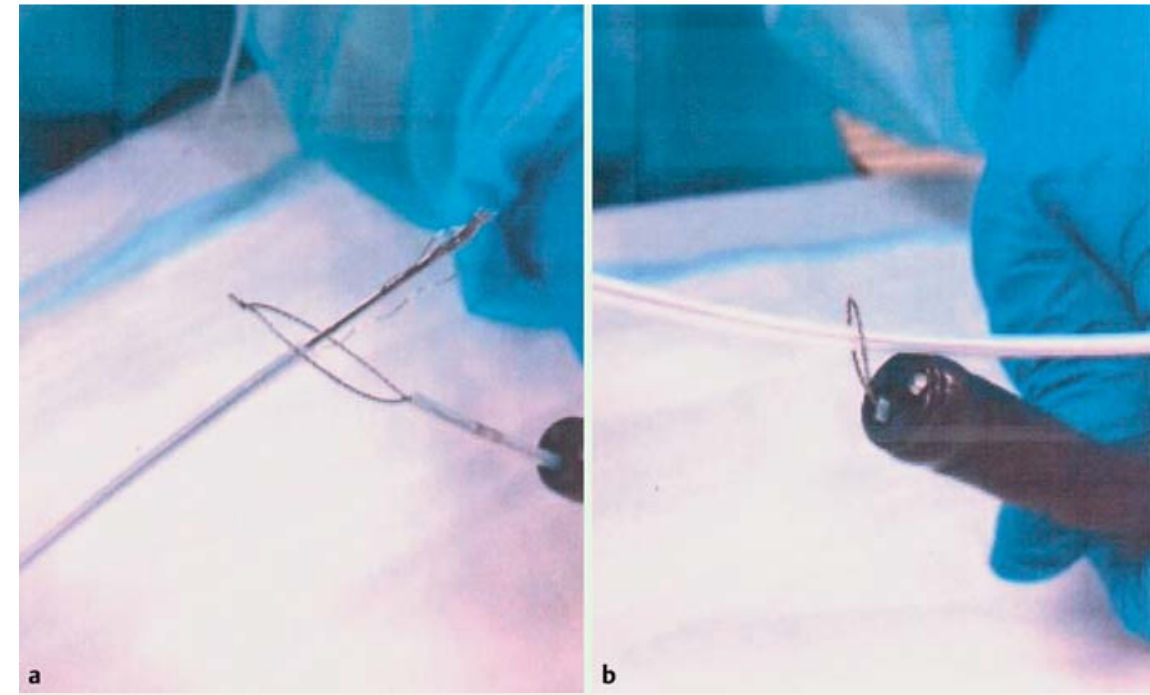

Fig. 2 Photographs showing: $\mathbf{a}$ insertion of the entrapped-snare wire through the second snare; $\mathbf{b}$ the zip-line configuration, with the colonoscope appearing to hang on the wire of the entrapped snare.

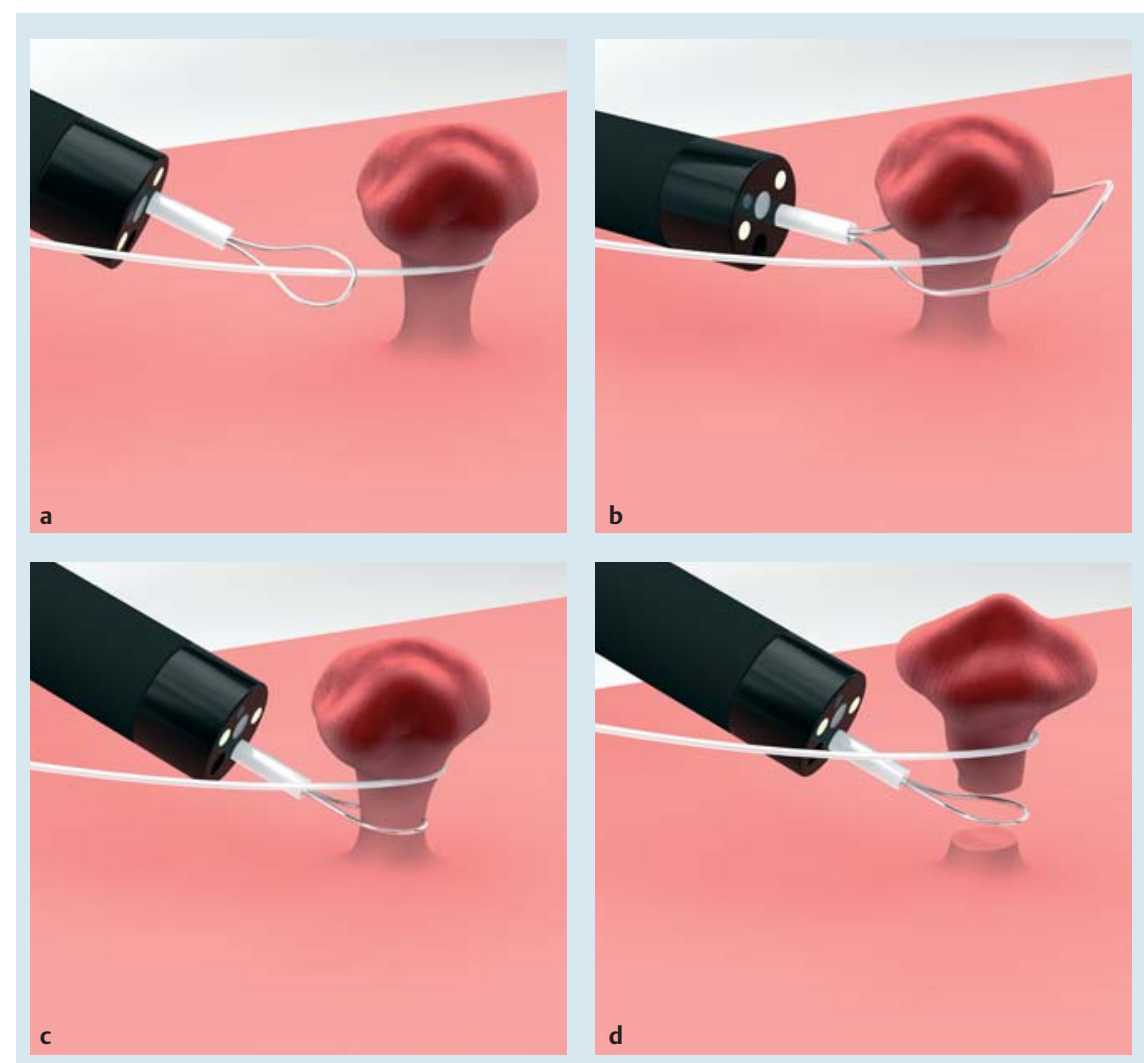

Fig.3 Schematic showing: a the polyp with the entrapped snare surrounding it being approached using the zip-line technique; $\mathbf{b}$ the zip-line snare being opened around the polyp; $\mathbf{c}$ the new snare being closed below the entrapped snare; $\mathbf{d}$ the polypectomy being successfully performed. 


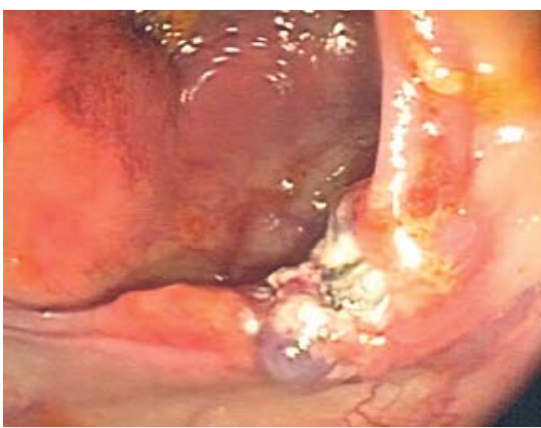

Fig. 4 Endoscopic view showing the site immediately after the polypectomy had been performed.

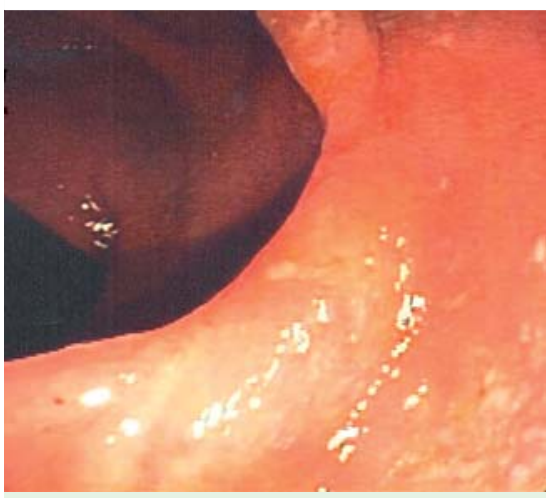

Fig. 5 View of the ascending colon during an endoscopy performed 3 months later showing no residual adenomatous tissue at the polypectomy site.
The snare was opened ( $\bullet$ Fig.3b), easily positioned below the entrapped snare $(\bullet$ Fig. $3 c$ ), and then closed. Blended current was then used to transect the polyp without difficulty ( $\bullet$ Fig.3d). After an inspection for polypectomy adequacy ( $\bullet$ Fig.4), the snare-entrapped polyp was removed along with the colonoscope.

Pathology of the polyp revealed a tubulovillous adenoma. A repeat colonoscopy performed 3 months later showed no residual adenomatous tissue ( $\bullet$ Fig. 5 ).

Risk factors for polypectomy-snare entrapment include ensnaring too much tissue, using too low a coag setting during polypectomy resulting in tissue charring around the snare, and frank malignancy. Attempts at nonsurgical management have included needle-knife polyp transection [1] and the use of cautery forceps for targeted piecemeal tissue removal around the entrapped snare in attempts to free it [2].

We report a technique that uses endoscopic equipment normally stocked in an office-based endoscopy setting. Inserting the entrapped wire through the newly placed open snare allowed the second snare to be easily positioned below the entrapped one and the polypectomy to be completed. We propose that the zipline technique be considered as first-line management for polypectomy-snare entrapment.

Endoscopy_UCTN_Code_CPL_1AJ_2AD

Competing interests: None
Robert D. Herman ${ }^{1,2}$, Michael E. Herman ${ }^{3}$, Carline Etienne², Sharareh Kavosh ${ }^{2}$, Pavanaja Reddy ${ }^{4}$

${ }^{1}$ Department of Medicine, Hofstra North Shore-LIJ School of Medicine, Hempstead, New York, USA

${ }^{2}$ Goldstein, Siegel, Herman, Kwak MD PC, Great Neck, New York, USA

${ }^{3}$ Department of Medicine, Mount Sinai St. Luke's-Roosevelt Hospital Center, New York, New York, USA

${ }^{4}$ Department of Anesthesia, Hofstra North Shore-LIJ School of Medicine, Hempstead, New York, USA

\section{References}

1 Lucia CF, Loudon R, Linder JD et al. Endoscopic removal of a snare entrapped around a polyp by using a dual endoscope technique and needle-knife. Gastrointest Endosc 2003; 57: $126-128$

2 Pezzoli A, Cifalà V, Simone $L$ et al. Fracture and entrapment of a snare as a complication of colonoscopic polypectomy. Endoscopy 2007; 39: E9

\section{Bibliography}

Dol http://dx.doi.org/

10.1055/s-0034-1392674

Endoscopy 2015; 47: E451-E452

(c) Georg Thieme Verlag KG

Stuttgart · New York

ISSN 0013-726X

\section{Corresponding author}

\section{Robert D. Herman, MD}

310 East Shore Road Suite 206

Great Neck

NY 11023

USA

Fax: +1-516-487-2868

rsmab@aol.com 